\title{
SUCESSO EM CONCURSOS PÚBLICOS: UM ESTUDO SOBRE MEMÓRIAS E PRÁTICAS DE LEITURA EM SUJEITOS QUE INGRESSARAM NA CARREIA PÚBLICA FEDERAL
}

Rita Signor ${ }^{1}$

\section{RESUMO}

O objetivo deste estudo é traçar o perfil leitor de vinte sujeitos que ingressaram na carreira pública federal por meio de aprovação em concursos muito concorridos. Os dados foram gerados por meio de questionário com perguntas discursivas dirigidas para a investigação das memórias (GUEDES-PINTO, 1995) e práticas de leitura desses sujeitos. As bases que orientaram a análise foram Galvão (2004), Lahire (2008), Barton, Hamilton e Ivanic (2000), Kleiman (1995) e Street (1993;1995). Os resultados sugerem configurações de perfis "esperadas" em relação às trajetórias de leitura. Contudo, o percurso leitor de um dos sujeitos revelou uma configuração, que distante das influências familiares e escolares, colocou em evidência outras formas de mediação que foram determinantes para que o sujeito chegasse à elite escolarizada.

Palavras-chave: Memórias e práticas de leitura. Perfil leitor. Letramentos situados.

\section{INTRODUÇÃO}

Nas últimas décadas, ampliou-se a noção de que a educação formal é uma importante maneira de promoção do desenvolvimento social. Contudo, no Brasil, apesar de avanços no acesso aos cursos universitários, ainda são poucos os que conseguem alcançar a universidade. Podemos imaginar, igualmente, que uma minoria consegue aprovação nos mais disputados concursos públicos do país. Pensando neste último grupo, realizamos as seguintes questões de pesquisa: Quem são esses sujeitos? Como conseguiram vencer centenas de concorrentes por cada vaga e garantir um lugar almejado por parte expressiva da população? Qual a relação deles com a leitura? O que leem? Como leem? Gostam de ler? Esses 
sujeitos são oriundos de entornos socioculturais favoráveis ao desenvolvimento do letramento? Ainda, qual o sentido da leitura nas suas vidas? A leitura diversa (não apenas a técnica), segundo a opinião deles, contribuiu de alguma forma para 0 sucesso no concurso? Se não, o que foi decisivo para o sucesso na prova escrita? Assim, através de discussões realizadas em torno dessas questões, o objetivo deste estudo é traçar o perfil leitor de uma amostra de vinte sujeitos/funcionários públicos federais. Para tanto, elaboramos um questionário com perguntas discursivas relacionadas às memórias (infância e adolescência) e práticas de leitura por eles realizadas, almejando, pelo estudo dessas trajetórias, contribuir para reflexões acerca das condições de letramento da população do Brasil, neste caso, de um grupo específico de brasileiros.

\section{A POPULAÇÃO INVESTIGADA}

Os vinte sujeitos deste estudo são todos do sexo masculino, com idades entre 31 e 49 anos, funcionários públicos federais, e exercem os seguintes cargos públicos: Perito Criminal Federal - PCF - (Polícia Federal); Engenheiro Civil (Caixa Econômica Federal) e Auditor Fiscal (Tribunal de Contas). Os sujeitos exercem suas funções nas seguintes áreas: engenharia civil, engenharia florestal, engenharia química, ciências da computação, geologia, farmácia, agronomia, medicina veterinária, contabilidade e engenharia elétrica. Com relação ao Estado de nascimento, um dos sujeitos é do Paraná, quatro são do Rio Grande do Sul, um é de Minas Gerais, dois deles são do Rio de Janeiro, um é da Paraíba, seis são de Santa Catarina, um é da Bahia, um é do Distrito Federal, um de São Paulo e dois sujeitos são do Ceará. Dentre os pesquisados, três têm pós-graduação em nível de doutorado, cinco em nível de mestrado e quatro em nível de especialização. Três sujeitos acumulam duas graduações. Com relação à escolaridade dos pais, doze dos vinte sujeitos têm os pais (pai e/ou mãe) com nível universitário, sendo que sete desses doze possuem pai e mãe com nível superior ou pós-graduação; seis deles possuem pais com nível médio de escolarização (ambos os pais) e um dos sujeitos a mãe possui nível fundamental e o pai nível médio. Apenas um dos participantes da pesquisa possui ambos os pais com nível fundamental. Considerando que este último se distanciou dos outros em relação à escolarização dos pais e, levando em 
conta sua condição de sucesso escolar e profissional, pedimos a ele que nos concedesse também uma entrevista oral.

Desse modo, temos como dados de pesquisa vinte questionários respondidos e uma entrevista gravada em áudio. O objetivo da entrevista foi aprofundar a compreensão e análise dos dados por meio de confronto de um caso particular com as informações mais abrangentes das condições de letramento do grupo pesquisado. A seleção dos sujeitos ocorreu por meio de um contato da pesquisadora com um dos sujeitos que, mostrando-se interessado em ajudar, enviou e-mails para vinte e oito colegas em situação similar a sua. Dos vinte e oito sujeitos, dezenove se dispuseram a responder às questões. Os questionários foram enviados e respondidos por e-mail. A entrevista com um dos sujeitos foi facilitada em virtude de a pesquisadora residir na mesma cidade do entrevistado.

O questionário foi composto por dois blocos de perguntas, além dos dados de identificação. O primeiro bloco tematizava questões direcionadas às memórias de leitura (GUEDES-PINTO, 2005) dos sujeitos. O segundo bloco, por sua vez, apresentava perguntas direcionadas para as práticas de leitura.

De posse dos dados, procedemos à análise quantitativa e qualitativa, considerando as respostas dos sujeitos. A análise dos dados foi fundamentada nos Estudos do Letramento. Os pressupostos teórico-metodológicos aqui adotados remetem principalmente às pesquisas de Galvão (2004); Kleiman (1995); Barton, Hamilton e Ivanic (2000), Rojo (2009), Ribeiro (2004) e Street (1993; 1995).

A seguir, apresentamos a análise dos resultados. A seção três trata das memórias de leitura dos sujeitos e, na sequência (seção quatro), há a análise de suas práticas leitoras. Por fim, na seção cinco, apresentamos reflexões sobre a trajetória de um dos sujeitos da amostra pesquisada. Os participantes são representados por meio de iniciais de seus nomes.

\section{MEMÓRIAS DE LEITURA}

Nesta seção, discutimos as principais questões relacionadas às vivências pregressas (infância e adolescência) dos sujeitos no que se refere à participação em eventos e práticas de letramento.

Com relação à questão Seus pais (ou outras pessoas) liam para você quando você era criança?, tivemos como resultado que $60 \%$ dos sujeitos tiveram, durante a 
infância, alguma pessoa que lia para eles com certa regularidade. Importante comentar que alguns sujeitos disseram não lembrar se leituras eram realizadas para eles, mas não descartaram essa possibilidade, algo que podemos verificar no discurso de Al. "Não me lembro, mas acho que sim, porque eles [os pais] liam bastante e leem até hoje." Outros sujeitos revelaram que as histórias não eram lidas, mas contadas, algo que observamos nas palavras de T. "a gente ouvia muita história em disco ou fita cassete". S., por seu turno, relatou: "Meus pais, como também outros parentes, não tinham o hábito de ler histórias para mim quando criança. Meu avô materno era um contador de histórias, mas as mesmas não eram lidas". R. do mesmo modo, relatou: "Meus familiares não liam histórias para mim, mas eles contavam algumas histórias. Meu avô era um contador de causos, reunia os netos em volta dele e contava muitas histórias. Até hoje, com 92 anos, ele faz isso, só que com os bisnetos".

Ao analisarmos a questão, é importante considerarmos a época em que os sujeitos viveram a infância e adolescência, por volta das décadas de 1970 e 1980 . Segundo Silveira (2008), a década de 70 representa uma virada da tradição oral, em que os contos passam, além de serem contados, lidos. Sabe-se que os clássicos da literatura infantil surgiram de histórias da tradição oral. Natural, então, que nessa fase de transição muitos dos sujeitos ainda estivessem inseridos em uma tradição (oralista) de contação de histórias. Pelos dados, quase $40 \%$ dos sujeitos não se recordavam das leituras, mas de familiares contando histórias, um número ainda expressivo, se formos considerar que os pais, em sua maioria, pertenciam à classe média e tinham boas condições de escolaridade. Julgamos que a ênfase dada às atividades de leitura para crianças foram aumentando com o decorrer dos anos, com a preocupação crescente com a formação dos filhos e a mobilidade social, de modo que se sujeitos mais jovens tivessem respondido à pergunta, provavelmente, 0 índice de pais lendo histórias para eles na infância seria maior, se levarmos em conta as mesmas condições sociais das famílias. Tal consideração vai ao encontro da análise do resultado do INAF (Indicador Nacional de Alfabetismo Funcional $\left.{ }^{2}\right) / 2001$, uma vez que, segundo Galvão (2004), quanto mais jovem o entrevistado, maiores as chances de ter convivido com a diversidade de materiais de leitura e com pais com maior domínio da leitura e escrita. A autora associa esses resultados à crescente democratização do acesso à escola. 
Vale ressaltar que a familiaridade com a leitura desde criança pode ser decisiva para o sucesso escolar (LAHIRE, 2008) e este pode ser decisivo para o sucesso profissional. Para o autor,

\begin{abstract}
a leitura em voz alta de narrativas escritas, combinada com a discussão dessas narrativas com a criança, está em correlação extrema de 'sucesso' escolar com a leitura. Quando a criança conhece, ainda que oralmente, histórias escritas lidas por seus pais, ela capitaliza - na relação afetiva com seus pais - estruturas textuais que poderá reinvestir em suas leituras ou nos atos de produção escrita. (LAHIRE, 2008, p. 20).
\end{abstract}

Lahire diz ainda que o livro e os outros materiais escritos fazem parte das ferramentas do cotidiano pelos quais a criança recebe afeto dos pais, fazendo com que a criança associe afeto e leitura.

Sobre se seus pais liam para eles mesmos com frequência?, obtivemos $85 \%$ de respostas afirmativas. Esse percentual é elevado e corrobora a noção de que o exemplo dos pais pode ser um favorecedor da motivação pela leitura. Lahire (2008, p. 20) relata que o fato de ver os pais lendo pode passar aos filhos um aspecto natural à prática de ler, cuja identidade social poderá formar-se principalmente por meio deles: "ser adulto como seu pai ou mãe significa, naturalmente, ler livros...". Galvão (2004), analisando os dados do INAF/2001, observou que $29 \%$ dos entrevistados afirmaram nunca terem visto seus pais lendo, no entanto, esse percentual sobe para $88 \%$ quando os entrevistados encontram-se no nível 3 de alfabetismo $^{3}$. Dessa forma, o alto percentual de pais leitores "fecha" com os dados deste estudo que traz sujeitos com alto grau de escolaridade. Entretanto, o sujeito entrevistado ${ }^{4}$ afirma que seus pais não eram leitores, pois não os via lendo, além de serem pouco escolarizados, algo que o distancia do grupo nesse quesito e que, portanto, mereceu uma análise um pouco mais minuciosa, como dito antes. A singularidade das histórias revela como as trajetórias de letramento se distinguem, mostrando variáveis diferentes que se interpõem nas diversas histórias entre os leitores e as leituras.

Com relação à leitura de professores para os alunos, $74 \%$ responderam que seus professores liam textos literários em sala de aula, pelo menos em algum momento do processo de ensino. Sobre se gostavam de ler durante a infância $e$ adolescência, $74 \%$ responderam que sim. No entanto, $48 \%$ revelaram que a leitura não fazia parte de suas atividades favoritas. A pergunta que questionava se alguém havia motivado o gosto pela leitura revelou que, em $68 \%$ dos sujeitos, algum familiar 
motivou o gosto pela leitura. Os demais revelaram que não houve uma pessoa em particular responsável por fomentar o gosto por ler. Nenhum dos sujeitos citou professores como motivadores da leitura.

Algumas respostas dadas pelos sujeitos com relação ao quesito leitura $e$ escola merecem algumas considerações. Por exemplo, An. disse com relação à pergunta se realizava as leituras sugeridas pela escola: "Infelizmente, sim". T., por sua vez, disse: "Sim, mas normalmente naquela época eu lia o que era necessário ler. Não lia por prazer". Já C. relatou o seguinte: "Sempre. No entanto, na maioria das vezes sem prazer, porque os temas ou a forma de escrever dos autores não me despertavam curiosidade". F., por seu turno, revelou aversão à avaliação escolar pós-leitura: "Sim, sempre realizava as leituras indicadas, muito embora não tivesse muito interesse em desenvolver as atividades relativas à verificação da leitura". I., do mesmo modo, também manifestou desagrado às leituras escolares: "Sim, mas sinceramente as achava chatíssimas. Às vezes não eram indicadas à minha idade, ou eram simplesmente ruins." Cabe ressaltar que a forma como a escola tem introduzido seus sujeitos ao "mundo da leitura" não tem mudado muito atualmente. Mesmo no caso de sujeitos que são oriundos de entornos familiares favoráveis ao desenvolvimento do letramento, como no caso dos sujeitos deste estudo, é comum referirem que as atividades de leitura e escrita desenvolvidas não motivavam o prazer pela leitura, que as aulas de Língua Portuguesa eram centradas no ensino da gramática e que as leituras sugeridas eram desinteressantes tanto quanto a cobrança que se fazia delas, as ditas práticas de didatização.

Kleiman (1995), no que diz respeito às práticas de letramento desenvolvidas na escola tradicional, salienta que estas subjazem uma concepção sustentada num modelo parcial e equivocado: 0 dominante ${ }^{5}$. Esse modelo pressupõe uma certa unidirecionalidade de desenvolvimento associado à mobilidade e progressos sociais, que se reproduz, conforme Kleiman, desde o século passado com os movimentos de educação em massa. A escola, muitas vezes, oculta seus sujeitos, sua história, seus entornos, seus interesses e, como consequência, não consegue atingir seus alunos, despertar desejos em relação ao objeto do conhecimento. Mesmo no caso dos sujeitos desta pesquisa, que já vinham de um ambiente familiar "propício" para o desenvolvimento do gosto pela leitura, mesmo esses, a escola não seduz. A grande maioria que referiu gostar de ler delegou a membros da família, e às leituras realizadas em casa (as não sugeridas pela escola), o desejo pela leitura. Podemos 
constatar essa afirmação quando da pergunta: você realizava leituras não sugeridas pela escola?

Vamos nos reportar aos mesmos sujeitos citados anteriormente. An. referiu: "Sim, claro" opondo-se ao anterior infelizmente. T. que havia dito que não lia por prazer as leituras indicadas pela escola, respondeu: "Sim. Lembro de ler bastante por puro prazer. Sempre tive interesse em lugares diferentes. Eu gostava bastante de Geografia". C., contudo, relatou: "Durante o ensino fundamental e médio eu raramente lia alguma obra fora do que era indicado pela escola". Importante comentar que provavelmente C. relacionou leitura à literatura (obra literária?) para responder às perguntas, um complicador metodológico em decorrência do instrumento de pesquisa (questionário). Talvez se tivéssemos realizado uma entrevista, teríamos explorado outras leituras. F., por sua vez, marcou seu distanciamento das leituras escolares e mostrou sua aproximação às não escolares: "Sim, frequentemente as leituras traziam curiosidade sobre outros livros". I. que havia dito que as leituras indicadas pelas escola eram ruins, quando da pergunta se lia outras leituras não indicadas, referiu: "Principalmente".

Nesse contexto, cabe a pergunta: se sujeitos oriundos de entornos propícios ao desenvolvimento da relação de proximidade com a leitura, mostraram certo distanciamento daquilo que era proposto pela escola, o que supor dos que pertencem às classes sociais desfavorecidas? Nesse cenário, é possível compreender por que muitas pessoas sequer conseguem atingir a habilidade básica de decodificação. A situação se complica porque muitos dos professores, eles mesmos, possuem vivências restritas de letramento, conforme Kleiman.

Das memórias às práticas de leitura, passamos ao segundo bloco de perguntas que visava conhecer a relação atual dos sujeitos com a leitura.

\section{PRÁTICAS DE LEITURA}

Com relação à pergunta: Sobra tempo para leitura fora do ambiente de trabalho?, $20 \%$ dos sujeitos disseram restar pouco ou muito pouco tempo para ler fora do trabalho. Com relação ao gosto pela leitura, dois dos sujeitos disseram que não gostam de ler, um deles disse que gosta pouco, outro ainda revelou um gosto moderado pela leitura, e os demais, $80 \%$ (16 sujeitos), revelaram que gostam de ler. Deste último percentual, quatro sujeitos disseram que adoram ou gostam muito de 
ler. Sobre a frequência de leitura (fora do trabalho), dois dos sujeitos responderam que leem quase diariamente, outros dois disseram que leem em média umas três vezes por semana e os demais revelaram o hábito de ler diariamente, representando um total de $80 \%$.

Em relação à pergunta sobre o que leem, os materiais de leitura mais citados foram: livros técnicos $(11)^{6}$, artigos científicos (10), leituras na internet (10), revistas (9), literatura (9), jornal (6), livros sobre História (5), livros sobre viagens (5), livros religiosos (5), livros de filosofia (3), livros sobre arte (2), biografia (2), teses (2), livros de direito (2), e outras leituras foram citadas apenas uma vez como maçonaria, livros de economia, auto-ajuda etc.

Os assuntos que mais despertam a vontade de ler, segundo os sujeitos, são: política (12), economia (12), História (10), esporte (10), assuntos gerais (como notícias) (10), religião (6), assuntos técnicos (5), turismo (4), ciência (2), cotidiano (2), automóveis (2), mercado de ações (2), filosofia (1) e animais (1).

É interessante comentar que os livros técnicos foram citados como os mais lidos pelos sujeitos. Street (1995) menciona a expressão letramento escolar, resultado da pedagogização do letramento social. No INAF, por exemplo, os livros didáticos (59\%) e apostilas (56\%) foram os mais citados entre os estudantes que deveriam indicar o que costumavam ler. Segundo Street (1995) e Heath (1983), o letramento social passa pelo crivo do letramento escolar, sendo que as leituras escolares se tornam padrão para as modalidades não escolares. Neste estudo, podemos fazer menção a letramento funcional, ou seja, aquilo que se lê para o trabalho e em decorrência dele. Assim, na amostra pesquisada, percebemos que o que mais se lê está relacionado à função profissional, algo que tende a influenciar as práticas sociais de leitura. Nesse caso, não podemos falar em pedagogização, como propõe Street, mas em funcionalização do letramento social. No entanto, vale comentar que em detrimento de os participantes da pesquisa relatarem que leem mais leituras voltadas para o trabalho, podemos observar que os assuntos de maior interesse não são os relacionados à profissão, sendo os mais citados política, economia, esporte, História, religião e assuntos gerais.

Julgamos que a pedagogização ou funcionalização do letramento social, desse modo, é um tema bastante complexo e requer o conhecimento de outras noções, como a de letramentos situados. O que deve ser sempre considerado são questões envolvidas na história dos sujeitos individuais e dos grupos sociais, nos 
quais estão envolvidos e, dessa forma, temos de pensar em múltiplos letramentos (ROJO, 2009), pois os eventos e práticas de letramento (STREET, 1995) são inúmeros e variáveis. Ainda, temos de considerar que os múltiplos letramentos são situados (BARTON, HAMILTON, IVANIC, 2000) no espaço e tempo, tendo, portanto, suas próprias especificidades.

Soares (2004) formula a hipótese que letramentos sociais e escolares pertencem a distintos espaços e tempos, mas estão inseridos nos mesmos processos sociais mais amplos, explicando por que vivências com a linguagem escrita no contexto da escola acabam por habituar os indivíduos em experiências sociais e culturais relacionadas à leitura no contexto que não o da escola. É possível hipotetizarmos algo semelhante em relação ao letramento funcional, principalmente se for considerar que, nos dias de hoje, com o avanço de pesquisas em todas as áreas em ritmo muito acelerado, se o indivíduo não se atualizar constantemente "perde-se", tornando-se um profissional obsoleto. A necessidade de leituras é grande para manter o sujeito competitivo e atuante e ele tem consciência disso. No entanto, apesar de a leitura da área técnica ter maior peso na vida dos indivíduos, estas não estão entre as preferidas, como já mencionamos. Se voltarmos à noção de letramentos situados, temos de nos voltar para os sujeitos em análise. Gostam de política, economia, História e esporte por quê? Quem são essas pessoas? Como vivem? Esses assuntos preferidos não estão, de certo modo, relacionados à vida social e profissional dos sujeitos?

Pensamos que gostarem desses assuntos principalmente, pode estar relacionado ao fato de serem pessoas de classe média alta e altamente escolarizadas. Também o fato de conquistarem certo patamar na carreira, coloca-os em uma posição de sujeitos bem "informados", "atualizados", "críticos", "aptos", portanto, a se inserirem em discussões em níveis mais "elevados", requeridos pelo grupo social no qual estão inseridos. É possível imaginar que pessoas que não dominem determinados assuntos de seu grupo possam, de certa forma, ficarem "excluídas" das conversas sociais. O mundo atual, diz Infante (2004, p.116), faz com que as pessoas desenvolvam habilidades em "múltiplas dimensões". "O que fica evidente, além disso, é que cada um tenha desenvolvidas as competências que permitam continuar construindo novos e múltiplos conhecimentos". Para a autora, a ênfase na atualidade deslocou-se de uma superespecialização para uma base sólida visando uma formação para o trabalho. Diz ainda, que além das competências duras 
(técnicas), são necessárias as competências brandas, como o relacionamento social (capacidade comunicativa), que inclui conhecimentos de assuntos gerais e atuais. Podemos perceber que nesse cenário mais atual, há uma diminuição da imagem do nerd, aquele que, mergulhado em livros técnicos e científicos, sabe tudo sobre sua área de especialização e pouco sabe sobre o mundo à sua volta. Ganha espaço, desse modo, o sujeito igualmente capacitado, mas mais informado sobre tudo e que, em geral, lê leituras diversas e não apenas as de seu campo de atuação profissional.

A fim de complementar essa discussão, apresentamos alguns relatos dos sujeitos quando a pergunta foi o que te influencia a ler?: S. diz assim:"Gosto de ler livros que me acrescentem alguma coisa, que me tornem uma pessoa melhor, que me levem a refletir sobre o meu papel no mundo. Nesse ponto, a Bíblia é imbatível". L., por sua vez, relata: "Leio por prazer temas variados e assuntos técnicos e da atualidade para estar bem informado". R. diz: "Leio assuntos que possam repercutir na minha profissional e cotidiana, além de atualidades". A. relatou que lê sobre viagens porque gosta de viajar e por isso procura informações dos lugares que quer conhecer. Diz ainda que lê sobre esportes e política por interesse pessoal. A Política, diz ele, "ajuda a compreender como as coisas funcionam na realidade". Essas foram apenas algumas das respostas que usamos para ilustrar de que forma outros assuntos e não apenas os técnicos motivam a leitura nos sujeitos situados em contextos sociais bastante amplos.

Ao analisarmos o perfil leitor dos sujeitos, em situação de sucesso em concursos públicos, pudemos observar, como já mencionamos, que se trata de pessoas com práticas amplas de leitura. Contudo, ao analisarmos, sob o ponto de vista dessas pessoas, se o fato de lerem bastante, e leituras variadas, poderia de alguma forma contribuir para o resultado do concurso, tivemos respostas divergentes. Quatro dos vinte sujeitos acredita que não, que ser leitor de leituras variadas não influi no resultado do concurso. Atribuíram o sucesso no concurso às leituras técnicas. Vejamos um dos relatos:

No meu caso, que sou engenheiro elétrico, o que mais interfere é a capacidade de cálculo. Durante a graduação, eu sempre prestei muita atenção às aulas, fazia os exercícios e estudava muito. A graduação não requeria muita leitura, possivelmente por isso que eu optei em ser engenheiro. Antes de fazer a prova do concurso, verifiquei o programa e busquei na internet artigos relativos àquilo que eu não sabia nada, ou muito pouco, e os li. Não acredito que o hábito da leitura influencia muito na 
aprovação ou não em concurso; acho que é muito mais importante ter foco, ou seja, ler o que interessa e ter a capacidade de sintetizar o conteúdo lido. (E.)

Importante remetermos o relato de E. à sua história e sua relação com a leitura. E. revelou que seus familiares não liam para ele quando criança e que também os pais não liam para eles mesmos. Desse modo, ele teve pouca vivência em eventos de leitura em família. E até hoje é possível observar que a leitura não é atrativa para ele: "Na verdade eu não gosto de ler, eu leio pois é uma forma de obter informação. Quando há necessidade de obter uma informação eu busco livros, artigos, etc, sobre o assunto e leio. Ao contrário do que acontece com outras pessoas, para mim ler não é um prazer". O sujeito julga que a leitura não foi relevante para seu ingresso no concurso por relacionar leitura à fruição, à literatura talvez. Para ele, leitura é um meio de obter informações e é provável que esses conhecimentos adquiridos através da leitura tenham sido importantes para sua entrada na carreira pública.

Ac., por sua vez, também referiu que as leituras amplas não foram relevantes para seu sucesso no concurso:

No meu caso, em particular, acredito que a leitura diversa da técnica tenha
tido uma contribuição mínima, tendendo a nula. No concurso é cobrado
técnica e abstrações a partir dessa técnica. A preparação emocional conta
muito. Você precisa dominar o assunto que será cobrado e ter a habilidade
de associar isso aos elementos da prova. A cobrança é muito específica e a
capacidade de raciocínio desenvolvida na faculdade conta mais que as
habilidades literárias. (Ac.).

Como o sujeito E., Ac. relaciona leitura à literatura. E, da mesma forma que E., Ac não teve pais lendo para ele quando criança e também não observava os pais lendo para eles mesmos. Ac., como E., se vê como alguém que não gosta de ler, algo que podemos observar em suas palavras: "De modo geral nunca gostei [de ler]. A coisa piorava quando tinha de ler coisas muito longas. Sempre gostei mais de leituras objetivas". Ac. relacionou a pergunta à leitura-fruição. Para ele, como podemos observar no excerto, "a capacidade de raciocínio desenvolvida na faculdade conta mais que as habilidades literárias". As leituras objetivas são para Ac aquelas não-literárias e ele referiu ler com frequência: livros religiosos, sobre política, viagens, esporte; sendo assim, é leitor ávido e não se dá conta disso à medida que relaciona leitura à literatura principalmente. 
Para os que referiram não gostar de ler e, como consequência, que a prática da leitura pouco ou nada contribuiu para o resultado do concurso, é em decorrência de considerarem que um leitor de fato é um alguém que lê obras literárias e que sente prazer com isso; é como se o leitor "legítimo" (BOURDIER, 2007) fosse o de literatura, aquele que lê por fruição.

No entanto, percebemos que grande parte dos sujeitos revelou que o hábito de ser leitor de leituras variadas pode contribuir para o concurso, uma vez que influi na capacidade de redigir textos (redações que são exigidas no concurso), melhora a capacidade de raciocínio e interpretação das questões da prova. Cabe ressaltar que, pelas respostas, é possível que se observe a concepção de leitura dos sujeitos. Vejamos alguns relatos:

A pessoa que lê tem seus horizontes ampliados, conhece coisas e lugares que não esteve pessoalmente, além de ter sua capacidade de redigir textos aperfeiçoada - o que é essencial nos concursos que tenham prova de redação. (I.)

No caso do concurso que fiz, e boa parte dos concursos concorridos, há uma prova discursiva. Entendo que para escrever bem é necessário ler bastante. (G.)

A leitura seria uma forma de organizar as ideias e escrever melhor, ampliar o universo de palavras usadas. (Al.)

Em todos os concursos públicos nos quais fui aprovado, a começar pelo próprio vestibular, o bom desempenho nas provas de português e redação foi decisivo para a minha aprovação. Foi, digamos assim, o diferencial. No meu entendimento, isso é fruto de anos e anos de assiduidade aos livros, que me permitiram ter um conhecimento não limitado à minha área profissional $[\ldots](\mathrm{S}$.

O hábito de ler textos variados possibilita o aumento do teu nível de informação, amplia teu vocabulário, e tende a facilitar a tua forma de se expressar em uma conversa e também em uma redação. Entretanto, conheço pessoas que leem muito e não tiveram êxito em concursos. (L.)

Nas provas de concurso público é muito importante a interpretação de textos que só se desenvolve com a leitura. (M.)

Ler otimiza os processos de pensamento e raciocínio, as faculdades cognitivas e aumenta os conhecimentos gerais e cultura. (R.)

Não me considero uma pessoa que lê muito, mas acho que a leitura é fundamental para melhora da capacidade de expressão e amplia os conhecimentos. Acho que é importante para um bom desempenho em concursos, mas é um processo de muitos anos, impossível de ser iniciado em função do objetivo de passar num concurso. [...]. (Ra.)

Acredito que a leitura e a escrita estão extremamente interligadas. Quem lê mais, tem a oportunidade de compreender diferentes pontos de vista sobre um mesmo tema e isso torna a pessoa mais crítica. A leitura estimula o 
raciocínio e desenvolve o vocabulário. Acho que os textos escritos (redações) por pessoas que leem tendem a ser muito melhores. (T.).

Podemos observar, pela análise das respostas apresentadas, que a concepção dominante em relação à leitura pelos sujeitos é a do senso comum. Assim, acreditar que quem lê bem escreve bem - como se houvesse uma relação de "espelhamento" entre as práticas de leitura e de escrita; que a leitura otimiza os processos de pensamento; que ler permite à pessoa que se expresse melhor; que amplia as ideias e o horizonte são noções hegemônicas que merecem alguma problematização. É certo que a leitura implica uma maior capacidade de verbalização e criticidade, mas algumas concepções predominantes perfazem o que Kleiman (1995) denomina de mitos do letramento. Olson (1994) diz, por exemplo, sobre a relação entre escrita e cognição, que a introdução da escrita numa sociedade não produz mudanças cognitivas gerais, como a capacidade de memorizar, classificar e derivar inferências lógicas. A raiz dos efeitos cognitivos importantes, se é que eles são reais, precisou ser procurada em outro lugar, como na alteração das condições sociais ou dos processos de aprendizado.

É importante considerar que os participantes apresentaram sua "concepção" de leitura por meio de uma resposta a uma pergunta que tentava correlacionar concurso e leitura. Desse modo, natural que remetessem suas considerações às condições de produção da prova, que exigem do candidato conhecimentos vários, necessidade de interpretar questões, muitas vezes complexas, em um curto espaço de tempo e, por fim, a exigência de uma redação, algo que podemos observar nas palavras de T.: "A leitura estimula o raciocínio e desenvolve o vocabulário. Acho que os textos escritos (redações) por pessoas que leem tendem a ser muito melhores". Neste trecho é possível observar uma concepção de que quem lê tem mais a dizer do que quem não lê. Discordamos desse ponto de vista, no entanto, é evidente que o que é exigido nas redações supõe um conhecimento de mundo de indivíduos leitores, bem como adequação à norma padrão da língua.

A seguir, traçamos com mais detalhes o perfil leitor de um dos sujeitos desta pesquisa. 


\section{TRAJETÓRIA DE UM DOS LEITORES}

Marcelo tem 36 anos de idade, é casado, tem um filho e reside na cidade de Florianópolis. Prestou dois concursos públicos. No primeiro foi aprovado para a função de engenheiro civil na Caixa Econômica Federal, obtendo a $41^{\circ}$. colocação dentre doze mil candidatos. No segundo e último concurso ficou em 12‥ lugar na disputa por uma vaga de Perito Criminal Federal com cerca de cinco mil outros concorrentes (engenheiros civis).

Marcelo frequentou apenas instituições públicas de ensino, do primeiro ano do ensino fundamental ao doutorado em uma universidade federal. Passou no vestibular da UFSC aos 17 anos.

Durante a infância, trabalhou desde os 8 anos de idade na cidade de 3000 habitantes onde nasceu, no interior do Rio Grande do Sul. Atuou como vendedor de picolés e entregador de fonogramas ${ }^{7}$. Aos 14 anos, teve de se mudar para uma cidade maior, a $70 \mathrm{~km}$ de sua cidade natal, pois onde morava não havia o ensino médio. Na cidade "grande" trabalhava durante o dia, transportando sacos de cereais, e estudava à noite. Segundo ele, teve de trabalhar desde criança, pois seu pai exigia. Quando foi sair de casa para estudar na cidade maior, encontrou resistência por parte de sua mãe, que queria tê-lo por perto, mas Marcelo estava decidido a prosseguir seus estudos, mesmo sem a motivação dos pais. O pai trabalhava em um pequeno mercado na cidade onde moravam, e a mãe trabalhava como telefonista e auxiliar de professora em uma creche. A mãe de Marcelo cursou os primeiros anos do ensino fundamental, e o pai finalizou o ensino fundamental. Segundo o filho, seus pais não tinham o hábito da leitura. Afirmou, contudo, observar sua mãe lendo fotonovelas algumas vezes e também receitas de culinária. Quanto ao pai, algumas raras vezes o viu folheando um jornal.

No que diz respeito à sua trajetória de leitura, Marcelo mencionou que, quando era criança, lia histórias em quadrinhos: "Não sei como, mas apareceu um gibi lá em casa, eu comecei a ler e adorei, depois disso não parei mais. Todo o dinheiro que eu ganhava eu comprava gibis". Porém, a leitura foi reduzida quando o pai comprou uma televisão. "Diminuiu um pouco por conta da TV, mas como à noite não tinha nem desenho nem o Sítio [do Picapau Amarelo], então eu voltava para os meus gibis". Relatou, ainda, que a retirada da leitura era um tipo de castigo que 
acontecia quando ele não se comportava bem: "Quando eu aprontava alguma, minha mãe já tirava o gibi".

Marcelo não se lembra de ter realizado outras leituras durante a infância e que à época da adolescência, no ensino médio, leu apenas os livros indicados pela escola. "Não tinha tempo, trabalhava muito e à noite ia para a escola". Da mesma forma, na faculdade, não teve amplas experiências com a leitura: "Eu lia muito, mas só livros de engenharia, estudava muito, não sobrava mais tempo pra nada". Revelou, entretanto, que nos anos que se seguiram, após sua formatura, teve oportunidade de ler os romances que não havia lido: "Comecei a ler sem parar, li de tudo: O Homem que calculava, Grande sertão: veredas, Crime e castigo [...] adorei o Poderoso chefão, li muitos romances, revistas também, jornais, tudo. Depois que tive meu filho, diminuí bastante o ritmo, leio um romance de vez em quando, adorei os do Dan Brown, mas leio menos sim, com certeza. Aproveito para ler quando estou viajando (viagens constantes a trabalho) [...]". Sobre suas leituras de forma geral, além dos romances, Marcelo afirmou ler diariamente sobre política, economia, direito e as notícias veiculadas pela internet.

Analisar a trajetória desse sujeito, tão particular, tão distante do que se poderia esperar, pode nos conduzir a algumas reflexões, quando o objetivo é construir relações entre formação leitora e aspectos sociais e históricos. Galvão (2004), ao analisar se a leitura é algo que se transmite entre as gerações, salienta o quão é relevante a pesquisa de trajetórias individuais, uma vez que as estatísticas tendem a enquadrar indivíduos, homogeneizando trajetórias distintas. Desse modo, fazemos nossa a pergunta da autora:

\begin{abstract}
Se os dados analisados indicam as grandes tendências da relação estabelecida entre as gerações anteriores e a transmissão do hábito da leitura para os mais jovens, na medida em que revelam as experiências da maioria dos entrevistados, poderíamos nos perguntar o que faz com que a outra parcela da população estudada - que, em muitos casos, representa um número bastante significativo - rompa a barreira do óbvio e, por exemplo, mesmo tendo pais analfabetos ou com pouca escolarização, não tenham convivido com materiais de leitura em casa durante a infância, pertençam às camadas populares, sejam moradores de pequenas cidades ou da periferia das capitais, gostem de ler? (GALVÃO, 2004, p.142).
\end{abstract}

A nossa questão, entretanto, ultrapassa a posta acima, uma vez que Marcelo, além de gostar de ler, chegou à elite escolarizada, alcançando cargos públicos bastante disputados. A questão é: de que forma um menino de classe popular, que 
cresceu em uma cidade de 3000 habitantes, e que teve pouca participação em eventos de letramento em família, alcançou o sucesso escolar e profissional e desenvolveu uma relação intensa com a leitura? Além dos aspectos familiares, ele revelou que não houve a presença de algum professor em especial, ou atividades em sala de aula que pudessem ter despertado seu interesse pela leitura.

Galvão (2004), ao estudar trajetórias particulares de sujeitos leitores, analisou duas histórias, chegando à conclusão de que, mesmo pertencentes às classes populares, esses sujeitos tiveram familiares que foram decisivos por fomentar 0 gosto pela leitura. A história de Marcelo, contudo, distancia-se de um perfil marcado por influências familiares e escolares, colocando em evidência outras formas de mediação relacionadas à constituição leitora.

Ao observar o discurso de Marcelo, podemos perguntar: O sujeito desenvolveu uma relação particular com a leitura em razão do primeiro gibi que "apareceu" em sua casa? É possível que estivesse ali há muito tempo, mas não havia despertado o interesse até que o menino fosse alfabetizado. O relevante foi o acesso ao que - para ele - se tornou um "elemento de diversão". Marcelo morava em uma pequena cidade que, conforme suas palavras, trazia poucos atrativos. Segundo ele, uma das suas atividades de lazer era brincar com os amigos na rua, mas sua mãe não gostava que ele brincasse fora de casa, longe do olhar dela, então a leitura foi uma fonte de entretenimento importante, quase que exclusiva em sua vida. Também não tinha muitos brinquedos, praticamente só os que ele mesmo fazia. Interessante notar que o despertar para a leitura, por meio da história em quadrinhos, pôde ser perpetuado por Marcelo. Como ele trabalhava desde criança, tinha recursos para poder adquirir os gibis. Cabe ressaltar que ele não tinha que oferecer a renda recebida para sua família, como acontece com muitas crianças oriundas de famílias populares.

Outra questão que nos chamou a atenção foi sua mãe usar a retirada da leitura como forma de castigo. Pensamos que tal atitude acabou por reiterar o afeto de Marcelo pelas leituras das histórias em quadrinhos, uma vez que o que se costuma retirar, como punição à criança, são artefatos considerados "mais prazerosos" (televisão, brinquedos, jogos etc.) e não livros, o que pode ter alimentado no sujeito a noção de que os gibis eram fonte de entretenimento e não de obrigação (de ler). 
Esse caso parece ilustrar uma relação particular com a leitura. Percebemos que vários fatores confluíram para isso. Assim, encontrar um gibi "perdido" em sua casa, ter a oportunidade de lê-lo, poder usar o dinheiro que ganhava para comprar outras revistinhas, não ter televisão durante certo tempo em sua casa, não poder brincar fora de casa sem a supervisão materna, entre outros, foram aspectos que, certamente, "agiram" propiciando uma relação de proximidade com a leitura. É possível acreditar, desse modo, que nem os pais nem os professores agiram de forma direta na relação de Marcelo com as práticas leitoras.

No que concerne ao seu sucesso nos concursos, o sujeito delegou às leituras técnicas, ao estudo sistemático e alta capacidade de concentração, as possíveis razões de seu desempenho. No contraponto, disse que as leituras gerais influenciaram nas formas de verbalização no momento de escrita da redação.

\section{CONSIDERAÇÕES FINAIS}

Este estudo foi ao encontro dos achados de outras pesquisas na medida em que mostrou que o contato com a leitura desde a infância é um condicionante para desenvolver nos sujeitos relações mais produtivas em torno de práticas leitoras na idade adulta.

A questão posta aqui, contudo, tentou desvendar não apenas o gosto por ler, mas, além disso, traçar o perfil leitor de pessoas que ingressaram na carreira pública por meio da aprovação em concursos muito concorridos. Pensamos que entornos socioculturais favoráveis (pais altamente escolarizados, contato precoce e contínuo com a leitura, acesso a bens culturais, residir em cidades com recursos), como foi possível observar, foram importantes para que se tornassem leitores plenos, o que contribuiu para que alcançassem o sucesso nesses concursos. Percebemos, no entanto, ao analisarmos a trajetória de Marcelo, que outros fatores, além dos citados, podem influenciar na relação com a leitura. A trajetória de Marcelo, no que diz respeito ao aspecto sociocultural, não coincidiu com a dos outros sujeitos da pesquisa, revelando que a família e a escola podem não ser as únicas responsáveis por iniciar e condicionar a relação de indivíduos com as práticas leitoras.

Torna-se, então, relevante, que mais pesquisas sejam realizadas com o intuito de analisar como investimentos singulares em torno das práticas de leitura e escrita ocorrem nos diferentes segmentos sociais, sobretudo, nos sujeitos oriundos 
de classes sociais desfavorecidas. A pergunta que se coloca é: por que alguns sujeitos se distanciam do que seria "esperado" e revelam certa autonomia nas suas trajetórias de indivíduos leitores? Resposta essa que se oculta nos resultados dos indicadores como o INAF. O letramento, conforme Galvão (2004), tem de ser pensado e analisado em contextos específicos para que possamos refletir com maior profundidade sobre as condições de letramento dos brasileiros.

\title{
NOTAS
}

${ }^{1}$ Fonoaudióloga e doutoranda em Linguística pela Universidade Federal de Santa Catarina. Pesquisadora do GELCE (Grupo de Estudos em Linguagem, Cognição e Educação) - UFSC/CNPq. E-mail: ritasignor@gmail.com.

${ }^{2}$ O INAF avalia as condições de alfabetismo de uma amostra de 2000 pessoas brasileiras entre 15 e 64 anos. Neste artigo são apresentados dados do exame de 2001, uma vez que Ribeiro e colaboradores (2004) no livro "O letramento no Brasil" realizaram estudos a partir desses dados.

${ }^{3}$ Considerado o nível pleno de alfabetismo, que pode denotar habilidades leitoras complexas, como a capacidade de realizar inferências. Ressalta-se que desde 2001, quando o INAF começou a ser realizado, até 2011, não houve avanço da população em relação ao nível 3, oscilando em torno de $25 \%$ da população do Brasil.

${ }^{4}$ Lembramos que um dos sujeitos, além de responder ao questionário, também foi entrevistado.

${ }^{5}$ Em oposição a esse, Street $(1993$, p.7) descreve o modelo ideológico que "vê as práticas de letramento como indissoluvelmente ligadas às estruturas culturais e de poder da sociedade e reconhece a variedade de práticas culturais associadas à leitura e à escrita em diferentes contextos".

${ }^{6}$ Em parênteses consta o número de ocorrências em que o material de leitura foi citado pelos sujeitos.

${ }^{7}$ Os moradores da cidade ligavam para a telefonista e ditavam uma mensagem. Marcelo entregava as mensagens escritas aos seus devidos destinatários.

\section{SUCESS IN FEDERAL PUBLIC CONCOURSE: A STUDY ABOUT READING MEMORIES AND READING PRACTICES OF SUBJECTS WHO STARTED FEDERAL PUBLIC CARRIER}

\begin{abstract}
The purpose of this study is to outline the profile of readers who started their federal public carrier after being approved in examinations with a great number of candidates. The bases that guied the study was Galvão (2004), Lahire (2008),
\end{abstract}


Kleiman (1995), Street (1993;1995), Barton, Hamilton e Ivanic (2000). Our data was found after applying a quiz with discursive questions whose objective were to enable an investigation about memories (GUEDES-PINTO, 1995) and reading practices of these candidates. The results appointed to already expected profiles. However, there was a different case: one of the readers was far from the influences of family and school and had different forms of mediation that were decisive to his reading proficiency.

Keywords: Memory and reading practice. Readers profiles. Situated literacy.

\section{REFERÊNCIAS}

ABREU, M. Os números da cultura. In: RIBEIRO, V. (Org.). Letramento no Brasil. São Paulo: Global, 2004. p. 33-45.

BARTON, D.; HAMILTON, M. IVANIC, R. (Eds.). Situaded literacies: reading and writing in context. London: Routledge, 2000.

BATISTA, A.; RIBEIRO, V. Cultura escrita no Brasil: modos e condições de inserção. Educação \& Realidade, Porto Alegre, n. 2, v. 29, p. 89-134, 2005.

BOURDIER, P. A economia das trocas simbólicas. São Paulo: Perspectiva, 2007.

GALVÃO, A. M. Leitura: algo que se transmite entre as gerações? In: RIBEIRO, V. (Org.). Letramento no Brasil. São Paulo: Global, 2004. p. 122-145.

GUEDES-PINTO, A.L. Percurso de letramento dos professores: narrativas em foco. In: KLEIMAN, A.; MATENCIO, M. (Orgs.). Letramento e formação do professor: práticas discursivas, representações e construção do saber. São Paulo: Mercado de Letras, 2005, p. 65-89.

HEATH, S. Ways with words: language, life and work in communities and classrooms. New York: Cambridge University Press, 1983.

INFANTE, I. Educação e capacitação permanente. In: RIBEIRO, V. (Org.). Letramento no Brasil. São Paulo: Global, 2004. p. 115-121.

KLEIMAN, A. Os significados do letramento: uma nova perspectiva sobre a prática social da escrita. Campinas: Mercado de Letras, 1995.

LAHIRE, B. Sucesso escolar nos meios populares: as razões do improvável. São Paulo: Ática, 2008. 
OLSON, D. R. The world on paper: the conceptual and cognitive implications of writing and reading. New York: Cambridge University Press, 1994.

RIBEIRO, V. Uma perspectiva para o estudo do letramento: lições de um projeto em curso. In: KLEIMAN, A.; MATENCIO, M. (Orgs.). Letramento e formação do professor: práticas discursivas, representações e construção do saber. São Paulo: Mercado de Letras, 2005. p. 17-39.

(Org.). Letramento no Brasil. São Paulo: Global, 2004.

ROJO, R. Letramentos múltiplos: escola e inclusão social. São Paulo: Parábola, 2009.

SILVEIRA, R. Ela ensina com amor e carinho, mas toda enfezada, danada da vida. Educação \& Realidade, Porto Alegre, n. 2, v. 22, jul/dez 1997.

SOARES, M. Letramento e escolarização. In: RIBEIRO, V. (Org.). Letramento no Brasil. São Paulo: Global, 2004. p. 89-113.

STREET, B. Cross-cultural approaches to literacy. New York: Cambridge University Press, 1993.

. Social literacies: critical approaches to literacy in development, ethnography and education. London: Longman, 1995. 